\title{
Mathematics for teaching: What is it and why is it important that we talk about it?
}

\author{
Jill Adler \\ Marang Centre for Mathematics and Science Education, University of the Witwatersrand \\ Email: adlerj@educ.wits.ac.za
}

\section{Introduction}

I begin this paper ${ }^{1}$ with a brief discussion of what can be considered systemic 'problems' in mathematics education before moving on to the research problem I am currently investigating. This broad introduction will help locate the QUANTUM $^{3}$ research project - a study of the mathematical work of teaching - that forms the substantive part of this paper. I will describe the research we are doing, its questions and objects. I will discuss some initial findings, what this research suggests for mathematics educators in the tertiary and school sectors, and so why it is important that we (communities of mathematics educators, and mathematicians) talk about it.

\section{Systemic problems in mathematics education}

Mathematicians often ask me: "What are the major problems in mathematics education? What progress has been made by mathematics education researchers in solving these?” These are typical of the way a mathematician would ask questions about research in mathematics, where the field advances through the increasing solution of outstanding problems. ${ }^{4}$ Education, and by

\footnotetext{
${ }^{1}$ This paper is based on a plenary talk presented at the South African Mathematical Society (SAMS) Conference, Potchefstroom, November 2004. I would like to take this opportunity to thank AMESA (The Association for Mathematics Education of South Africa) for the honour bestowed on by the invitation to deliver a plenary address at the 2004 SAMS Conference. The paper presentation will be published in the September 2005 Notices of SAMS, the Society's newsletter.

2 I use 'problem' here to indicate an area of inquiry, that which needs systematic and informed investigation, an area of social life about which we seek understanding and improvement.

3 QUANTUM is the name given to an R\&D project on mathematics qualifications for teachers in South Africa. The development arm of QUANTUM completed its tasks in 2003. QUANTUM continues as a collaborative research project. Zain Davis, from the University of Cape Town, has been pivotal in developing the theoretical orientation and approach to data. Current co-investigators include Diane Parker from the University of KwaZulu Natal, and Lyn Webb from the Nelson Mandela Metropolitan University and Mercy Kazima who is a Post Doctoral fellow at Wits.

${ }^{4}$ I acknowledge Professor Hyman Bass, President of the International Commission for Mathematical Instruction (ICMI) and Professor Deborah Ball, for many interesting and engaging conversations about the work of mathematicians and its contrast with mathematics education.
}

implication, mathematics education, is a very different research field. Problems are not as well defined, nor are they solved once and for all. There is, however, an established and thriving field of mathematics education research with advances in knowledge about the teaching and learning of mathematics, and how to research and improve these complex domains of social life. In this paper I describe this research as a study of 'problems' intentionally to enable discussion between mathematicians and mathematics educators on a significant shared 'problem'.

Without detracting from the contribution of small-scale investigations into teaching and learning mathematics, there are identifiable systemic problems in mathematics education. ${ }^{5}$ At the most basic level, we have yet to understand how to make mathematics learnable by all children. With pressure on Higher Education Institutions for better throughput, this issue is one that now concerns us at all levels. It is interesting to note here that there are currently discussions between the IMU (International Mathematical Union) and the ICMI (International Commission for Mathematical Instruction) on a joint international study of what is called the "pipeline problem", and our shared concern that fewer people are taking up advanced study of mathematics. This threatens the development of the discipline itself, as well as the provision of scientists and engineers, not to mention the provision of mathematically well qualified teachers for our schools.

We have yet to understand what constitute the most effective interventions into key points or areas in the system. Is this at school/institutional level, in classrooms, or at the level of individual learners? Are the learning problems we see at all levels a function of curriculum? pedagogy? language? Or again a combination of all three?

\footnotetext{
${ }^{5}$ A number of papers in mathematics education were presented at the SAMS 2004 conference each of which is a small-scale study that relates in some way to common research thrusts, questions and problems in the wider field. The abstracts of these talks are available on the SAMS website: www.cam.wits.ac.za/sams/
} 
Thirdly, and this is my own area of interest, we do not yet know enough about the mathematical preparation and ongoing support that enables mathematics teachers to do a capable and skilful job. At this juncture of massification (where all in society are expected to be mathematically literate), we face an enormous challenge of providing large numbers of adequately and appropriately trained mathematics teachers, at a time when fewer are choosing teaching as a profession. ${ }^{6}$ We face a particular and new problem of scale of provision, and this again is a significant concern that mathematicians and mathematics educators are likely to share.

The question currently being investigated in the QUANTUM project, one I regard as also systemic, is what mathematics teachers (at different levels) need to know and know how to do, in order to teach well. While we obviously need to know this if we are going to effectively prepare large numbers of teachers across the system, the question emerges out of two additional concerns. Firstly, the curriculum teachers are now (in post 2000) expected to teach does not match their prior learning (in school or in teacher education). Not only are there new orientations to teaching mathematics (and other subjects), in mathematics there are new topics, topics teachers currently in practice have not learned e.g. data handling, applications and modelling. Secondly, and this is the more difficult area to conceptualise and understand, the mathematics that is used in teaching the curriculum is not synonymous with doing mathematics in other domains of practice (e.g. engineering, nursing, business). The kind of mathematical problem solving teachers do as they go about their work in school classrooms is less clear, yet critically important to understand.

\section{Mathematics teaching as mathematical problem solving ${ }^{7}$}

A few examples, what are usefully called problems of practice, will help to illuminate what is implied by the notion of mathematics teaching as a special kind of mathematics problem solving. I will begin with one area that is well known - error analysis. Mathematics teachers constantly deal with student errors and/or misconceptions. Here are two well known learner errors of interpretation of $-3(x+2)$.

$$
\text { - }-3(x-2)=-3 x-6
$$

\footnotetext{
${ }^{6}$ See Adler, Ball, Krainer, Lin and Novotna (2005) for further discussion of this issue and its implications.

${ }^{7}$ I am indebted to Deborah Ball and Hyman Bass for this insight and productive analysis of the mathematical work of teaching.
}

$$
\text { - } \quad-3(x-2)=(x-2)-3
$$

The mathematical roots of these errors are quite different. A teacher who faces these in class, needs to do on the spot analysis of the nature of the error, and its mathematical entailments, as well as what it means to engage learners productively to shift their thinking. At face value, the first response could be a slip, and if so, easily corrected. Not so the second response.

Another example that illuminates learner thinking in school is taken from a pilot Grade 9 examination set and carried out across many IEB (Independent Examinations Board) schools in the early 1990s. Learners were asked to read the following discussion between a teacher and two learners, and then to decide and explain which of the two answers was correct.

Teacher: Expand $(x+2)^{2}$

Lindi: $x^{2}+4 x+4$

Chris: $x^{2}+4$

An alarming and surprisingly large number of learners from across the spectrum of poor to well resourced schools answered as follows: "Both are right. If you use FOIL, ${ }^{8}$ then you get the answer Lindi gave. If you use exponents, then you get Chris' answer".

The interesting thing about both examples above is that while these errors are well known, they reoccur. Learners present these kinds of responses with consistency and conviction. Moreover, each of them reflects a troubling absence of mathematical reasoning. And so the question: What do teachers need to know and know how to do (mathematical problem solving) in order to deal with ranging learner responses (and so some error analysis), and in ways that produce what is usefully referred to as "mathematical proficiency", a blend of conceptual understanding, procedural fluency and mathematical reasoning and problem solving skills?

I take a third and final example here from a grade 8 Maths Lesson, ${ }^{10}$ and a classroom where mathematical proficiency, particularly mathematical reasoning, was evident as a goal. As part of a sequence of tasks related to properties of triangles,

\footnotetext{
${ }^{8}$ This is a heuristic often taught to remember binomial products. You multiply the Fisrt terms, then the Outer terms, the Inner terms and the Last terms.

${ }^{9}$ See Kilpatrick et al (2001) for an interesting illumination of the notion of mathematical proficiency and how it is an interweaving of five competencies: procedural fluency, conceptual understanding, adaptive reasoning, strategic competence and productive disposition. This notion is important as it cuts across attempts to polarize procedural fluency and conceptual understanding as if it were possible to me mathematically effective with either competence on its own.

${ }^{10}$ This example comes from an earlier study (Adler, 2001) focused on teaching mathematics in multilingual classrooms.
} 
a teacher gave her grade 8 classes the activity in Box 1.

Box 1. If any of these is impossible, explain why, otherwise draw it.

- Draw a triangle with 3 acute angles.

- Draw a triangle with 1 obtuse angle.

- Draw a triangle with 2 obtuse angles.

- Draw a triangle with 1 reflex angle.

- Draw a triangle with 1 right angle.

Learners worked on their responses in pairs. The teacher moved across the classroom, asking questions like: Explain to me what you have drawn/written here? Are you sure? Will this always be the case? This elicited different learner responses. Below are three learner responses to the second item: Draw a triangle with two obtuse angles.

Some learners reasoned as follows: "An obtuse angle is more than 90 degrees and so two obtuse angles gives you more than 180 degrees, and so you won't have a triangle because the angles must add up to 180 degrees."

Some said that it is impossible to draw a triangle with two obtuse angles, because you will get a quadrilateral. And they drew:

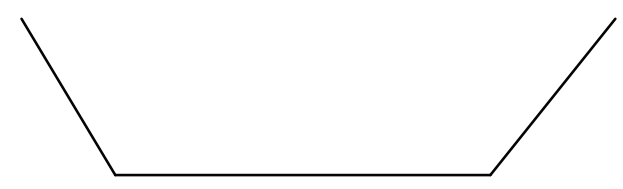

One learner and his partner reasoned in this way: "If you start with an angle say of 89 degrees, and you stretch it, the other angles will shrink and so you won't be able to get another obtuse angle." They drew:

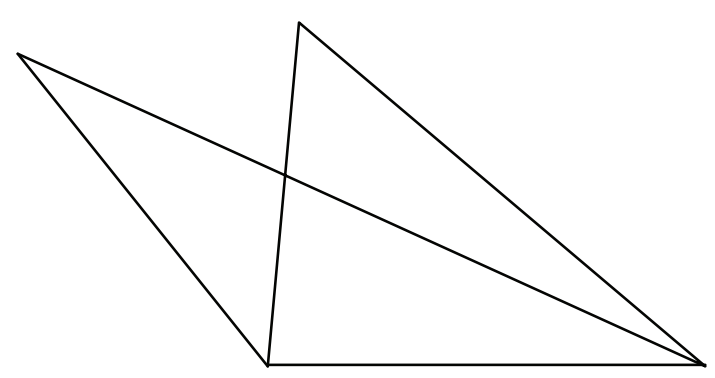

In the many diverse contexts where I have presented the study and this particular episode, much discussion is generated in relation to the mathematical status of the three responses, and their levels of generality, together with argument over what can be expected of learners at a grade 8 level. What constitutes a generalised answer at this level? Is Joe's response a generalised one? ${ }^{11}$ These are mathematical questions, and some of the mathematical work this teacher did on the spot as she worked to engage learners and their reasoning. In addition, the design of the task required the ability to work with multiple representations of mathematical notions in such a way that these could first be anticipated and then elicited. The teacher then needed to be able to judge the mathematical worth of learner productions which in turn would require being able to relate different responses to each other in relation to mathematics. Further mathematical demands for the teacher that are embedded in this task are the ability to work with definitions, relative to the community she is working with - grade 8 learners - and the ability to use language carefully to carry useful mathematical explanations.

Ball \& Bass (2000) and Ball, Bass \& Hill (2004: 59) describe these mathematical practices as elements of the specialised mathematical problems teachers solve as they do their work i.e. as they teach. They go on to look across these elements, and posit a more general feature. "Unpacking", they suggest, may be one of the essential and distinctive features of "knowing mathematics for teaching". They contrast this with mathematics and "its capacity to compress information into abstract and highly usable forms" and posit further that "Mathematicians rely on this compression in their work". Because teachers work with mathematics as it is being learned, they work instead with "decompression, or unpacking, of ideas" (emphases in the original).

There is growing support for the notion that there is specificity to the way teachers need to hold and use mathematics in order to teach mathematics - and that this way of knowing and using mathematics differs from the way mathematicians hold and use mathematics. Both mathematics and teaching are implicated in how mathematics needs

11 Joe's response is a dynamic one, based on visualising an angle changing size and the effect this can have on the triangle. The interesting thing here is that the kinds of technological tools (like Sketchpad) where a drag function enables this kind of exploration of related properties of all figures, was not available to Joe. His classmates found it difficult to follow his explanation. I noted earlier in the paper, the possible cognitive effects of learning geometry with tools that promote such visual and dynamic thinking. 
to be held so that it can be used effectively to teach. ${ }^{12}$

Unpacking or decompressing is a compelling description of the distinctiveness of the mathematical work that teachers do. The questions we need to now ask, and this will be the focus of the remainder of this paper, are: How/where is this specialised (practice-based) mathematical knowledge learned/taught? Where and how are prospective teachers provided with opportunities for learning to unpack mathematics, and so develop pedagogically useful mathematics?

\section{Researching the mathematical work of teaching: the QUANTUM project phase 1}

The above questions are in the foreground in the QUANTUM research project currently underway. We are investigating whether and how unpacked mathematics is evident in mathematics teacher education programmes. In Phase 1 (which has been completed, and so can be reported) we studied formal mathematics teacher education programmes across higher education institutions in South Africa, and focused on the following specific questions: What mathematical (and teaching) knowledges are being assessed in mathematics teacher education programmes? Is specialised (unpacked) mathematical knowledge assessed? Where? How?

As we set up the study, a first goal was to work across institutional sites. For practical and financial purposes, we restricted the survey to five of the nine provinces in South Africa, working across both urban and non-urban contexts, and also in those provinces where we knew such programmes were on offer. Both in South Africa, and internationally, the dominant empirical domain of studies in the context of mathematics teacher education are single cases (Adler et al., 2005; Adler, 2005; Krainer and Goffree, 1999). ${ }^{13}$ Our interest in an across site empirical sample was not for the basis of comparison, nor to identify good or better practice. Rather, it was with the intention of building a comprehensive and robust description of how and what mathematics was being privileged across contexts of practice and so insight into a general, as well as particular, construction of what

\footnotetext{
12 See Adler \& Davis (2004) for more detailed elaboration of the specificity of mathematics for teaching.

13 See Alexander (2000) for an interesting challenge to arguments of single case studies of teaching or classroom practice as being necessary for insight, thick description and authenticity. He argues convincingly that culture and pedagogy can be held in dynamic interaction and not necessarily fragmented in larger and cross-cultural empirical studies
}

is currently valued as mathematical knowledge for teaching.

The first task was to identify all such courses/programmes across the five provinces. We focused on mathematics-specific in-service qualifications, and particularly Advanced Certificates of Education (ACEs) designed for upgrading teachers' mathematics and teaching competencies. Sixteen such programmes came to light across thirteen different institutions spread across the provinces. We collected factual information on each course in each diploma so as to be able to identify whether they were courses in mathematics per se, mathematics education, or general education. We asked for details of average annual student intake, as well as the departments and faculties which taught these various courses.

Two institutions were offering an honours degree focused on mathematics education, that is, a programme one level higher than the ACE. We included the courses within these in our study. Of the eleven institutions offering ACEs, seven were offering a qualification for teachers across Grades 7 to 12, that is, across the Senior Phase (SP Grades 7 to 9) and Further Education Phase (FET Grades 10 to 12). One institution focused on SP only, and three on FET only. The average number of students in each cohort in each institution was \pm 50 , with four institutions taking in between 50 and 150 students. In two institutions, mathematics courses comprised $80 \%$ of the qualification, the remaining $20 \%$ being in general education courses. In most, the split tended to be 50\% mathematics, and 50\% mathematics education courses. In one, all courses combined or integrated mathematics and mathematics education. The courses were predominantly run and taught by mathematics teacher education staff. In seven institutions, some courses were offered from mathematics departments.

There are two interesting observations to make here. First, we were surprised by the relatively large numbers of practising secondary school mathematics teachers upgrading their qualifications by studying in ACE programmes across the country. This phenomenon of largescale formalised in-service teacher education at the secondary level marks out a specificity to mathematics teacher education in South Africa at present, a function of the legacy of apartheid education. The numbers were a further incentive for pursuing the study of the mathematics privileged in these programmes. Second, these programmes were designed specifically for teachers and were being contributed to by some 
Example 1a: From a calculus module

1.....

2. ....

3. Bereken elk van die volgende limiete indien hulle bestaan. /Evaluate each of the following limits if they exist.
(a) $\lim _{x \rightarrow 3} \frac{x^{2}-x+12}{x+3}$
(b) $\lim _{x \rightarrow 4} \frac{x^{2}-x-12}{x-4}$
(c) $\lim _{x \rightarrow 1} \frac{x^{3}-1}{x^{2}-1}$
(d) $\lim _{x \rightarrow 2} \frac{\frac{1}{x}-\frac{1}{2}}{x-2}$
(e) $\lim _{x \rightarrow 0} \frac{x}{\sqrt{1+3 x}-1}$
(f) $\lim _{x \rightarrow 1} \frac{\sqrt{x}-x^{2}}{1-\sqrt{x}}$

Example 1b: From an algebra module

1. In solving the equation $a x+b=c x+d$ we do things to both sides of the equation that can be "undone" (if we want).

(a) Make a list of the things we do and explain how they could be undone.

(b) You have to be carefully about one of these steps, because, depending on the value of a and $b$, you might do something which results in something meaningless. Explain.

\section{Example 2a}

Solve for $x: x^{2}-2 x=-1$

\section{Example 2b}

Here are a range of solutions to the equation $x^{2}-2 x=-1$ presented by Grade 10 learners to their class

Explain clearly which of these solutions is correct/incorrect and why

(a) Explain how you would communicate the strengths, limitations or errors in each of these solutions to the learners.

(b) What questions could you ask Learner 5 to assist her to understand and be able to formulate a more general response.

Learner 1: $x=1$ because if $x^{2}-2 x=-1$

then $x^{2}=2 x-1$ and $x=\sqrt{ } 2 x-1$

$x$ can't be 0 because we get $0=\sqrt{ }-1$

$x$ can't be negative because we get the square root of a negative

$x=1$ works because we get $1=1$ and no other number bigger than 1 works

Learner 2: $x=1$ because if $x^{2}-2 x=-1$

then $x(x-2)=-1$ and so $x=-1$ or $x-2=-1$

which leaves us with $x=1$ (because $x=-1$ does not hold true)

Learner 3: $x=1$ because if $x^{2}-2 x=-1$

then $x^{2}-2 x+1=0$ and this factorises to get

$(x-1)(x-1)=0$; so $x=1$

Learner 4: $x=1$. I drew the graphs $y=-1$ and $y=x^{2}-2 x$.

They intersect in only one place, at $x=1$.

Learner 5: $x=1$. I substituted a range of values for $x$ in the equation.

And 1 is the only one that works. 
mathematics departments in some institutions. It was equally interesting to see that there were cases where all courses, mathematics and mathematics education, were taught by mathematics teacher education staff either in schools of education, or in specialised centres for mathematics education within science faculties. This phenomenon could throw additional light on mathematics for teaching, and its emergence in courses in mathematics teacher education: on whether and how it is shaped by the wider mathematical/teaching discourses and practices of course presenters.

This initial survey was then extended to include an analysis of formal assessment tasks across courses. We found sufficient similarity in the kinds of courses across institutions to enable us to select four diverse programmes for detailed analysis. Three of these were ACE programmes. Focusing in on assessment tasks was a function of our drawing on the work of Basil Bernstein (1996). We selected Bernstein's sociological theory of pedagogy to assist in the construction of a principled gaze onto this complex terrain. ${ }^{14}$ According to Bernstein (1996) any pedagogy transmits evaluation rules. Evaluation condenses meaning, and transmits the criteria by which learners' displays of knowledge are judged. We thought that as a first phase in QUANTUM's research, it would be illuminating to examine the formal evaluation tasks in each of the courses in each programme. These would reveal, at least partially, the kinds of mathematical and pedagogical or teaching competencies that teachers in these courses were expected to display and so too the kind of mathematical knowledge privileged in these courses. In addition, we hoped the evaluation tasks would reveal whether unpacking of mathematics was valued, and if so, in what ways.

I have illuminated the notion of unpacking by discussing a few examples of the kinds of problems teachers solve as they go about their teaching. On the previous page there are examples of formal assessment tasks that illuminate what it might mean to assess unpacking as part of the mathematical competence teachers need. Examples $1 \mathrm{~b}$ and $2 \mathrm{~b}$ are assessment tasks that require demonstration of the kind of mathematical problem solving teachers face. These are examples of unpacking tasks. In contrast, Examples 1a and 2a are tasks that require the reproduction of some mathematical technique, and may or may not be a

\footnotetext{
${ }^{14}$ Much of this theoretical development has been led by Zain Davis, and is published as a QUANTUM working paper, See Davis et al. (2003)
}

reflection of the learners' (teacher's) ability to unpack the mathematical ideas related to these tasks.

\section{The research sites, coding scheme and results}

As already mentioned, we focused in on four sites. Sites 1 and 2 offered ACEs for senior secondary teachers, with $80 \%$ of courses in mathematics per se. The remaining course credits were in general education courses. Site 3 offered an ACE for secondary teachers, and here each course combined mathematics and mathematics education. From the assessments it appeared that the course was geared more to Senior Phase than Further Education teachers. Site 4 offered an honours programme, where the mathematics courses are explained as having a pedagogical eye, and vice versa. The mathematics education courses were expected to have a strong mathematical eye.

Before beginning systematic coding and analysis we had noticed that across the courses and tasks in Sites 1 and 2 there was a prevalence of tasks like Examples 1a and 2a above. In other words, a learner would be able to recognise quickly that a mathematical procedure or technique was to be displayed. There were also tasks that asked for more, for explication, or justification as well as a display of a problem response, as in Examples $1 \mathrm{~b}$ and $2 \mathrm{~b}$. And there were tasks that were recognisable for not being obviously mathematical, focusing instead on teaching.

We then developed a simple coding structure at the start: $\mathrm{M}$ to indicate a mathematical object of acquisition in the task, and $\mathrm{T}$ to indicate a teaching object. Most tasks could be categorised as either M or T. Each was then assessed as to whether the task object entailed unpacking, and if so, categorised as $\mathrm{U}$. U was indicated in relation to either of the objects $\mathrm{M}$ or $\mathrm{T}$, when more was demanded in the form of explication, justification, reflection, i.e. some form of unpacking. Some tasks summonsed mathematical and/or teaching contexts, but the mathematical or teaching knowledge entailed was either assumed to be known (and so the display not up for evaluation) or alternatively, the task involved a mathematical or teaching idea, but the object to be acquired was unclear or obscured. These were labelled $\mathrm{m}$ or $\mathrm{t}$. A list of codes and description of indicators follows:

$\mathbf{M}$ indicates a task that requires reproduction of a mathematical object, e.g. a definition or carrying out a previously learned procedure. That is all. As the constructivists have revealed, such a display cannot be necessarily associated with its 


\begin{tabular}{|l|l|l|l|l|l|l|l|l|l|l|}
\hline $\begin{array}{l}\text { Site } \\
\text { No. }\end{array}$ & $\mathbf{M}$ & Mt & MU & MUT & $\mathbf{m t}$ & $\mathbf{m T}$ & $\mathbf{m T U}$ & $\mathbf{T U}$ & $\mathbf{T}$ & Content of course \\
\hline 1 (ACE) & 25 & 25 & 50 & & & & & & & $\begin{array}{l}\text { Mathematics - From pre- } \\
\text { calculus, algebra, to } \\
\text { calculus, linear algebra }\end{array}$ \\
\hline 2 (ACE) & 93 & & 7 & & & & & & & $\begin{array}{l}\text { Mathematics } \\
\text { Calculus and linear } \\
\text { algebra }\end{array}$ \\
\hline 3 (ACE) & 30 & & 10 & 10 & 10 & 30 & & & 10 & $\begin{array}{l}\text { Mathematics and } \\
\text { mathematics methods }\end{array}$ \\
\hline $\begin{array}{l}\text { 4A } \\
\text { (Hons) }\end{array}$ & 8.5 & & 58 & 8.5 & 0 & 25 & & & & $\begin{array}{l}\text { Two Mathematics courses } \\
\text { (functions, geometry). }\end{array}$ \\
\hline $\begin{array}{l}\text { 4B } \\
\text { (Hons) }\end{array}$ & & & & 12.5 & & 12.5 & 50 & 25 & & $\begin{array}{l}\text { Four Mathematics } \\
\text { education courses } \\
\text { (connecting; expressing; } \\
\text { reasoning; assessing } \\
\text { maths) }\end{array}$ \\
\hline
\end{tabular}

Table 1: Categorisation of tasks in course assignments across sites, expressed as a percentage of the total number of tasks in each site/set of courses.

underlying concepts, nor with associated mathematical practices.

Mt indicates a task as in $\mathrm{M}$ above, but a teaching context is summoned, though its purpose is either irrelevant or obscure.

MU indicates a task that requires a reproduction of unpacked mathematics, e.g. demonstrating a grasp of the mathematical structure underlying the notion or mathematical object.

MUT indicates unpacked mathematics as above, but the task requires the unpacking to be explicitly related to tasks of teaching e.g. student errors, diverse responses, partial explanations, mathematical practices, e.g. reasoning, defining.

mt indicates that both or either mathematics and teaching contexts are summoned, but the object of evaluation is not clear, and so the production of the legitimate text is not clear.

$\mathbf{m T}$ indicates a task that requires reproduction of some aspect of knowledge of teaching, and a mathematical context is summonsed, though the mathematical knowledge entailed is assumed to be known.

mTU indicates a task that requires reproduction and reflection on an aspect of knowledge of teaching and the mathematical context used. A mathematical context is summonsed, though the mathematical knowledge entailed is assumed to be known.

TU indicates a task as above, but no specific mathematical context/object is called up or used.
$\mathbf{T}$ indicates reproduction of some aspect of knowledge of teaching, where, for example, the text produced could rely on memory alone.

Table 1 contains the analysis of each of the tasks or a set of tasks within an assignment, across selected courses in these four sites. The sites are numbered 1 to 4 in the first column. The tasks are referred to as evaluative events. (An) stands for Assignment n, (En) indicates this was an examination. The category or typing of each event is indicated in the particular column by a 1 . The end column contains some content information on the course within which these assignments occurred.

\section{Mathematical and teaching practices privileged in mathematics teacher education}

The categorisation of task types reveals most starkly that the mathematical knowledge privileged in mathematics courses in ACE programmes (Sites 1,2 and 3 ) is compressed mathematics - the ability to demonstrate mastery of procedures and underlying concepts (though the display in no way guarantees underlying conceptual understanding). A similar privileging was evident in assignment tasks in the mathematics courses in the remaining institutions in the survey that offered ACE upgrading programmes for secondary mathematics teachers. The topics in these courses across institutions included calculus and linear algebra, 
and were offered largely by lecturers in mathematics departments.

The problem facing mathematics teachers currently in practice, as these courses suggest, is that they don't know enough mathematics. An interesting contradiction here is that one of the major difficulties facing secondary teachers in schools today are the huge gaps in their learners' mathematical knowledge. They talk of continuing struggles with "the backlog". In this context, unpacking or decompression become more important, and indeed more demanding as teachers need to be able to trace back mathematical ideas and their antecedents with their learners.

Overall then, what was observed across these ranging ACE programmes is the persistence and dominance of compressed mathematics in formal assessment. Yet, the courses of which they are part were specifically designed for teachers. The courses are not part of mainstream mathematics courses, and so are not bound by mathematical goals, say, for undergraduate mathematics students. Moreover, ACE programmes, typically, are managed by mathematics teacher educators, most of whom would assert that to teach mathematics well, it is not enough to be able to do pieces of mathematics.

It is, however, interesting to observe that alongside the dominance of compressed formal evaluations, there are instances in the assignments in Sites 1 and $3,{ }^{15}$ and in an examination in Site 2 where a demonstration of unpacked or decompressed mathematics is required. Here is evidence of some sense of the value of unpacked mathematics for teachers. The question, of course, is why are these relatively rare in formal assessments?

In Site 4, that site where a higher-level programme is offered, there is a far wider range of tasks, and indeed some interesting issues in the mathematics courses which have input from both mathematics teacher education lecturers in the School of Education, and lecturers in the School of Mathematics. We were intrigued by the assessment tasks in the courses on functions and geometry and the ways in which formal evaluation emerged. The functions course evidences struggles over how mathematics is or is not in the foreground in formal assessments in courses where there is greater integration of the pedagogic on the one hand, and mathematical processes on the other.

\footnotetext{
15 There are additional interesting points about the analysis of assessments in Site 3 that have been discussed elsewhere (see Adler \& Davis, forthcoming; Adler, 2005) and are beyond the focus of this paper.
}

This stands in contrast to the geometry course, where most of the assignments demand an unpacking of mathematics, but without an explicit eye on mathematics teaching, hence the percentages reflected in the table above.

Of course, hard conclusions are inappropriate without a further examination of what and how evaluative events punctuate the flow of mathematics in classroom practice within these courses, and so whether there is more evidence there of unpacking as a valued mathematical practice in courses. If this is the case, then a further question to pursue is why formal evaluation then condenses mathematical meaning to produce the privileging of compressed mathematics we have seen. These are being explored in Phase 2 of the study.

In sum, the analysis reveals more the absence, rather than the presence of unpacked mathematics for teaching in these across-site evaluation tasks, despite the courses of which they are part being specifically designed for teachers. Why is this so? And what does this suggest for the preparation and ongoing support of mathematics teachers? What might this mean for each of the communities of mathematics educators and mathematicians, all of whom are involved, even if indirectly, in the preparation of mathematics teachers.

\section{Why is mathematical unpacking absent in mathematics teacher education assess- ment, and what does this imply?}

I conclude this paper with some speculative comments on why this is so. Firstly, and perhaps most simplistically, the absence of unpacked mathematics could be a function of this falling between what are typically subject (i.e. mathematics) and method (i.e. teaching) courses, as these are often offered by departments that remain quite insulated from each other. It is conceivable that lecturers in mathematics departments do not see this kind of mathematical problem solving as falling within the competencies that they are developing and assessing. At the same time, lecturers in mathematics education might not see this as falling within the scope of their courses, and expect this mathematical work to be done in the mathematics components of these programmes. Hence the title of this paper and my view that it is important that we (our two mathematics communities) talk about this.

More significantly, however, an explanation of this absence probably lies in the nature of this mathematical work, that it is not yet well enough understood and as a result it remains hard to teach 
and so is hard to assess. We have argued elsewhere (Adler \& Davis, 2004) that this kind of mathematical problem solving needs more careful and systematic description. The route to improved understanding is through further detailed study of the actual practice of mathematics teaching.

From observation and work with many in teaching, it is obvious that some teachers have learned 'on the job' to solve the mathematical problems they face, i.e. in their practice. At the same time, from years of experience in mathematics teacher education, both pre and inservice, I am aware that many practising teachers would be hard pushed to spontaneously answer questions like: "What mathematical question would you ask a learner who does ..." or "What are three possible, different solution strategies for ...”.

The question for us all then is: Is this kind of knowledge teachable? The analysis presented above reveals that across selected formalised programmes for mathematics teachers, and particularly at the level of the ACE, this kind of mathematical knowledge is not being assessed. While this does not necessarily mean it is not being taught, the empirical question remains, can it be taught, and then will it lever up the benefits we would want: more effective mathematical preparation and ongoing support for our teachers.

My goals in this paper have been to make a case for understanding mathematics teaching as a particular kind of mathematical problem solving, and then to show that in some of our mathematics teacher education programmes, teachers are not being assessed on this kind of mathematical knowledge. We know that assessment reflects what is valued. That teachers are not expected to demonstrate this kind of competence also suggests that they are not provided with opportunities to learn this kind of mathematics in their formal education and training.

It is my view that this 'problem' of the mathematical preparation and ongoing support of teachers is one that both communities of mathematicians and mathematics educators need to work on together. At a time when there is so much to do to foster and improve mathematics teaching and learning across all levels in South Africa, it is encouraging that our relevant communities are working together. ${ }^{16}$ The practices of

\footnotetext{
16 The establishment of the South African Mathematics Foundation (SAMF) reflects the increasing areas of co-operation between AMESA and SAMS, as do the invitations by each of SAMS and AMESA to the other to deliver plenary addresses at their respective
}

mathematicians and mathematics educators are very different, and often it is difficult for us to understand each other. Through more conversation and joint activity, we will hopefully learn to communicate across our different questions, orientations and priorities towards goals we share, and the common challenges we face.

\section{References}

Adler, J. (2001). Teaching mathematics in multilingual classrooms. Dordrecht: Kluwer Academic Publishers.

Adler, J. (2005). Researching mathematics teacher education: The QUANTUM project and its progress. In C. Kasanda et al (Eds.) Proceedings of the $13^{\text {th }}$ Annual Conference of the Southern African Association for Research in Mathematics, Science and Technology Education (pp. 11-24). Windhoek: UNESCO Namibia.

Adler, J. \& Davis, Z. (2004). Opening another black box: Researching mathematics for teaching in mathematics teacher education. Paper presented at AERA, April, 2004, Mimeo.

Adler, J., Ball, D., Krainer, K., Lin, F.L. \& Novotna, J. (2005). Reflections on an emerging field: Research on mathematics teacher education. Educational Studies in Mathematics, 61 (pages not yet known).

Alexander, R. (2000). Culture and Pedagogy. Oxford: Blackwells.

Ball, D. \& Bass, H. (2000). Interweaving content and pedagogy in teaching and learning to teach: Knowing and using mathematics. In J. Boaler (Ed.) Multiple perspectives on mathematics teaching and learning (pp. 83-104). Westport: Ablex Publishing.

Ball, D., Bass, H. \& Hill, H. (2004). Knowing and using mathematical knowledge in teaching: Learning what matters. In A. Buffgler \& R. Lausch (Eds.) Proceedings for the $12^{\text {th }}$ Annual Conference of the South African Association for Research in Mathematics, Science and Technology Education (pp. 51-65). Durban. SAARMSTE.

Bernstein, B. (1996). Pedagogy, Symbolic Control and Identity: Theory, Research, Critique, London: Taylor \& Francis.

conferences, and so too the context in which this paper was developed. 
Davis, Z., Adler, J., Parker, D. \& Long, C. (2003). Elements of the language of description for the production of data. Working paper 2, University of the Witwatersrand, School of Education, QUANTUM Research Project.

Kilpatrick, J., Swafford, J. \& Findell, B. (Eds.) (2001). The strands of mathematical proficiency. In Adding it up: Helping children learn mathematics (pp. 115-118). Washington: National Academy Press.
Krainer, K. \& Goffree, F. (1999). Investigations into teacher education: Trends, future research, and collaboration. In K. Krainer, F. Goffree \& P. Berger (Eds.), On research in Mathematics Teacher Education. European Research in Mathematics Education IIII. Osnabrück: Forschungsinstitut für Mathematikdidaktik.

"Let go of your attachment to being right, and suddenly your mind is more open. You're able to benefit from the unique viewpoint of others, without being crippled by your own judgement."

\section{Albert Einstein}

